Correction

\title{
Time Dependent Thomas Fermi Approach to Atomic Collisions II
}

High and Intermediate Energy Proton-Atom Scattering

\author{
M. Horbatsch and R.M. Dreizler \\ Institut für Theoretische Physik der Universität, \\ Frankfurt, Federal Republic of Germany \\ Z. Phys. A - Atoms and Nuclei 308, 329-338 (1982)
}

This paper was published erroneously under the sec-

tion "Nuclei"; it ought to have appeared under

"Atoms".

M. Horbatsch

R.M. Dreizler

Institut für Theoretische Physik

Universität Frankfurt/Main

Robert-Mayer-Strasse 8-10

D-6000 Frankfurt/Main 1

Federal Republic of Germany 